\title{
Eğitimde Yapay Zeka Konusunda Türkiye Adresli Çalışmaların İncelenmesi
}

\section{Mevlüde AKDENIZ*, Fatih ÖZDİNÇ ${ }^{* *}$}

Özet: Yapay zekanın eğitimde kullanılması son yıllarda gelişen bir alandır. Bu çalışmanın amacı yapay zekanın eğitimde kullanımı ile ilgili Türkiye'de yapılan çalışmaları sistematik olarak incelemektir. Çalışmada yapay zeka teknikleri incelenmiş, bu teknikler ile geliştirilen öğretim materyalleri ve bu materyallerin kullanımı alanyazına dayalı olarak ifade edilmiştir. Ulusal Tez Merkezi ve Türkiye adresli dergiler, belirlenen anahtar kelimelerle taranmıştır. Tarama sonucunda ulaşılan 37 araştırma, bu çalışma kapsamında betimsel içerik analizi yöntemi ile analiz edilmiştir. Eğitimde yapay zeka konusunda yapılan çalışmaların sayısında son yıllarda hızlı bir artış olduğu görülmüştür. Araştırmalarda en çok üniversite öğrencileri ile çalışma yapıldığı ve zeki öğretim sistemlerinin yaygın olarak kullanıldığı belirlenmiştir.

Anahtar Kelimeler: Yapay zeka, betimsel içerik analizi, eğitimde yapay zeka, zeki öğretim sistemi

\section{Examination of Turkey Addressing Studies Regarding Artificial Intelligence in Education}

Abstract: The use of artificial intelligence in education is a field that has developed in recent years. These studies were conducted in Turkey to use The aim of the study is to systematically examine the studies conducted in Turkey regarding the use of artificial intelligence in education. Artificial intelligence techniques were examined in the study, and the teaching materials developed with these techniques and the use of these materials were expressed based on the literature. Turkey addressed the National Thesis Center and journals were scanned with specified keywords. 37 studies obtained as a result of the scanning were analyzed using the descriptive content analysis method within the scope of this study. It has been observed that

\footnotetext{
* Bilim Uzman1, email: akdenizmevlude@gmail.com Orcid No: 0000-0002-6177-9260

** Dr. Öğr. Üyesi, Afyon Kocatepe Üniversitesi, Eğitim Fakültesi, Bilgisayar ve Öğretim Teknolojileri Eğitimi Anabilim Dalı, email: fozdinc@aku.edu.tr, Orcid No: 0000-0003-2150-5019

*** Bu çalışma 4. International Academic Research Congress (INES 2018)'de sunulan bildirinin genişletilmiş halidir.
}

\begin{tabular}{lll}
\hline Gönderim:15.01.2021 Kabul:15.03.2021 $\quad$ Yayın:25.05.2021 & Kab
\end{tabular}


there has been a rapid increase in the number of studies on artificial intelligence in education in recent years. It has been determined that studies mostly work with university students and intelligent teaching systems are widely used.

Keywords: Artificial intelligence, artificial intelligence in education (AIEd), descriptive content analysis, educational artificial intelligence, intelligent tutoring system

\section{Giriş}

Yeni pedagojik anlayışlar, etkili öğrenmenin nasıl gerçekleştirileceği, etkili öğrenme için tasarlanacak eğitim materyallerinin hangi özellikleri taşıması gerektiği konularının araştırılmasını önemli hale gelmiştir. Öğretmenler, öğrencilerin öğrenme sürecinde, onların zihinsel stratejileri ne zaman ve nasıl kullanacağını belirlemeli, öğrenme konusunda onları cesaretlendirmeli, öğrencilerin karmaşık düşünce yapılarıyla meşgul olmalarını sağlamalıdır (Nist, 2000). Ancak Covid-19 salgını ile beraber öğrenciler öğretmenlerinden fiziksel olarak uzakta kalmış ve öğrencilerin bireysel olarak öğrenme süreçlerini kontrol etmeleri daha önemli hale gelmiştir. Öğrencilerin kendi kendilerine öğrenme deneyimleri yaşamaları değer kazanmıştır Öğrencinin kendi kendine öğrenme sürecinde öğrenme amacına uygun materyallere ihtiyaç duyulmaktadır. Teknoloji ve yazılım konusundaki gelişmelerle birlikte, geliştirilen materyaller öğrencinin kendi kendine öğrenmesini desteklemenin yanı sıra öğretmenin rehberlik etme ve öğrenmeyi kolaylaştırma rolünü de üstlenebilmektedir. Eğitim materyalleri ve yazılımlar, yapay zeka ile donatılarak zeki canlılar gibi düşünme, soyutlama, öğrenme, yeni durumlara uyma, etkileşim sağlama gibi yeteneklere sahip olmaktadır (Uğur ve Kınac1, 2014). Yapay zeka bu özellikleri ile başta aktif öğrenme olmak üzere diğer öğrenme yöntemleriyle de birlikte kullanılarak eğitim alanında kendine yer bulmakta, bu konu ile ilgili yapılan araştırmaların sayısı artmaktadır.

Yapay zeka, bilgisayarın ya da bilgisayar tarafından kontrol edilen bir makinenin, insana özgü davranışlar olduğu düşünülen akıl yürütme, anlam çıkartma, genelleme ve geçmiş deneyimlerden öğrenme gibi zihinsel görevleri gerçekleştirme yeteneğidir (Öztemel, 2003). Yapay zeka ile ilgili çalışmaların sayısı artmakta ve birçok sektörde kullanılmaktadır. Yapay zeka uygulamalarında başlangıçta belirli teknikler üzerinde durulurken, kullanım alanları genişledikçe farklı yaklaşımlar da geliştirilmektedir. Yapay zeka kavramı tek başına bir teknolojiyi ifade etmemektedir. Makine öğrenme, doğal dil işleme, veri madenciliği, sinir ağları veya bir algoritma gibi bir dizi teknoloji ve yöntemi tanımlamak için kullanılan genel bir 
terimdir. Başlıca yapay zeka teknikleri; uzman sistemler, bulanık mantık, genetik algoritmalar, yapay sinir ağları ve zeki etmenler olarak gösterilebilir (Kuzu, 2018; Öngöz, 2020).

Makine ögrrenmesi, bilgisayarların, gözlemden ve gerçek dünya deneyimlerinden toplanan verileri, bilgileri işleyerek zaman içinde öğrenmelerini, insanlar gibi davranmalarını ve sürekli iyileşmelerini sağlayan bir alandır (Pala, 2020).

Uzman sistemler, bir konuda alanında uzman olan kişilerin bilgi ve tecrübelerinin bir bilgisayar ortamına aktarılmasıyla tasarlanmış olan, bu bilgi ve tecrübeleri kullanarak sistemlerde ortaya çıkan sorunlara uzman bir kişiye ihtiyaç olmaksızın çözümler üreten bilgi tabanlı sistemlerdir (Şahin, 2008). Uzman sistemler insan ve bilgisayarın birlikte karar verdiği durumlarda teşhis ve tavsiye niteliğinde bilgiler sunmaktadır. Uzman sistemler, oluşturulan geniş bilgi tabanını kullanarak karar verme sürecinde ortaya çıkabilecek belirsizlikleri en aza indirmektedir (Erçetin ve Baykoç, 2004).

Bulanık Mantık, tanımlamada ortaya çıkan belirsizlikleri gidermek için matematiksel ifadeler yerine sözel ifadeler kullanma esasına dayanan bir yöntemdir. Gerçek dünyada olaylar çok karmaşık durumdadır. Örneğin hava sıcaklığından bahsederken soğuk, serin, 1lık, sicak, çok sıcak gibi birçok ifade kullanılabilmektedir. Bu durumların yazılım hazırlama sürecinde matematiksel ifadelerle net olarak tanımlanabilmesi mümkün değildir. İncelenen bir konunun tam olarak sayısal verilerle ifade edilememesi ve bilinmemesi bulanıklık kavramını açıklamaktadır (Ünal ve Uygunoğlu, 2005).

Genetik algoritmalar, evrimsel hesaplama tekniği kullanarak çalışmaktadır. Bir probleme ait mevcut çözümlerden en iyisinin seçilmesi, uygun olmayan verinin elenmesi yöntemi, genetik algoritmaların mantığını oluşturmaktadır (Bolat, Erol ve İmrak, 2004). Geleneksel yöntemlerle çözümü zor ya da imkansız olan problemlerin çözümünde sıklıkla kullanılmaktadır.

Yapay sinir ăgları insan sinir sisteminden etkilenerek geliştirilmiştir. Yapay sinir hücreleri dış ortamdan aldığı verileri toplamakta, aktivasyon fonksiyonu ile çıktıyı üretmekte ve diğer hücrelere iletmektedir. Yapay sinir ağları, veriler arasındaki bilinmeyen ve fark edilmesi güç ilişkileri ortaya çıkartabilir (Hamzaçebi ve Kutay, 2004). Yapay sinir ağları, örnek olayları inceleyerek olaylar hakkında genellemeler yapmakta ve bilgiler toplamaktadır. Yeni bir örnekle karşılaştığında öğrendiği bilgileri kullanarak yeni sorunun çözümü hakkında karar verebilmektedir (Öztemel, 2003). 
Zeki etmenler, şartları sürekli olarak değişen bir çevrede, değişimle eş zamanlı olarak durumu algılama, düşünme ve verdiği kararı eyleme dönüştürme görevlerini yerine getiren sistemlerdir (Bekleriç, 2003). Zeki etmenler mevcut davranış seçenekleri içerisinden amaca uygun olanını seçerek kullanıcıya tepki vermekte ya da kullanıcıyla iletişime geçmektedir (Ünsal ve Şahingöz, 2011).

\section{Eğitimde Yapay Zeka}

Yapay zeka, sosyal etkileşimlerimizin her yönünü değiştirebilen, gelişen bir teknolojik alandır. Etkileşimlerimizi etkilemesinin kaçınılmaz sonucu olarak eğitim alanını da etkilemekte ve değiştirmektedir. Eğitimde yapay zeka, şu anda farklı bağlamlarda test edilmekte olan yeni öğretme ve öğrenme çözümleri üretmeye başlamıştır. Eğitimde yapay zeka uygulamalarının en sık rastlanan örnekleri, zeki öğretim sistemleri (ZÖS), uyarlanabilir öğrenme sistemleri ve öneri sistemleri olarak gösterilebilir. ZÖS, öğrenen için daha iyi destek sağlayarak öğrenmeyi geliştirmek için bir insan öğretmeni modellemek için yapay zeka tekniklerini kullanır (Hasanov, Laine \& Chung, 2019). Öneri sistemleri, birinin ilgisini çekebilecek potansiyel yararlı öğeler için öneriler sağlayan makine öğrenme ve bilgi alma tekniklerine dayalı yazılım araçlarıdır (Syed ve Zoga, 2018). Uyarlanabilir öğrenme ortamları, öğrenenlerin çeşitli özelliklerinden bir model oluşturarak onların gereksinimlerine uygun, bireyselleştirilmiş öğrenme ortamı sağlamaktadır (Somyürek, 2009).

Zeki öğretim sistemleri, kime, neyi, nasıl öğretmesi gerektiğini tahmin eden pedagojik bilgisayar programlarıdır. Yapay zekâ tekniklerini kullanıp öğrencinin öğrenme sürecindeki performansını değerlendirerek elde ettiği verilere göre eğitim programını düzenleyebilme, öğrencinin seviyesini belirleyebilme, öğrenci ile etkileşimde bulunma gibi yeteneklere sahiptir. Bir insan öğreticinin yapabildiklerini, öğrencinin seviyesine ve yeteneklerine uygun bir şekilde pedagojik öğretim tekniklerini kullanarak taklit edebilen bir sistemdir (Pramuthu, 2005). ZÖS, bilgisayarların işlevselliğini arttırarak öğretimin etkin şekilde gerçekleşmesini sağlamaktadır. $\mathrm{Bu}$ özelliği ile eğitimde devrim niteliği taşıdığı söylenebilir. ZÖS’ün tasarım aşamalarında eğitim öğretim teknolojileri, bilgisayar teknolojisi ve yapay zekâ bir arada kullanılmaktadır (Doğan ve Aktaş, 2011).

Yapay zekanın eğitimde kullanılması son yıllarda önem kazanmaktadır. Yapay zeka alanyazında eğitim ile ilgili kısım küçük bir yer kaplamaktadır (Arık ve Seferoğlu, 2020; Tahiru, 2021).Yapay zeka, eğitimde öğretmenlere yardımcı olarak ve öğrenenlerin anlamlı yaşantılar sağlayarak destekleyici bir rol almaktadır (How ve Hung, 2019). Son yıllarda robot 
teknolojisinin gelişmesi ile eğitimde yapay zekanın kullanılması ivme kazanmıştır. İnsansı robotlar Yuki ve Sophia, eğitim bağlamında da kullanılmaktadır (Retto, 2017).

Baker ve Smith (2019), eğitsel yapay zeka araçlarına a) öğrenciye dönük, b) öğretmene dönük ve c) sisteme dönük eğitsel yapay zeka araçları olmak üzere üç farklı bakış açısıyla yaklaşmaktadır. Öğrenciye yönelik yapay zeka araçları, öğrencilerin bir konuyu öğrenmek için kullandıkları, uyarlanabilir veya kişiselleştirilmiş öğrenim yönetim sistemleri veya ZÖS gibi yazılımlardır. Öğretmene dönük sistemler, öğretmeni desteklemek ve yönetim, değerlendirme, geri bildirim ve intihal tespiti gibi görevleri otomatikleştirerek iş yükünü azaltmak için kullanılır. Eğitsel yapay zeka araçları ayrıca, öğretmenlerin gerektiğinde destek ve rehberlik sunabilmesi için öğrencilerin öğrenme sürecine ilişkin iç-görü sağlamaktadır. Sisteme dönük eğitsel yapay zeka, örneğin fakülteler veya okullarda veri değişim modellerini izlemek için kurumsal düzeyde yöneticilere ve yöneticilere bilgi sağlayan bir araçtır.

\section{Çalışmanın Amacı}

Bu çalışmanın amacı belirlenen yapay zeka teknikleri ve ZÖS bağlamında Türkiye’de yapılan çalışmaları, nicelik, araştırma yöntemi ve eğilim açısından incelemektir. Bu amaç doğrultusunda çalışmada, yapay zeka tekniklerinin eğitimde kullanılması konusunda 19992018 yılları arasında yayınlanmış lisansüstü tezler, eğitim ile ilgili dergilerde ve Türkiye adresli uluslararası dergilerde yayınlanmış makaleler taranarak betimsel içerik analizi gerçekleştirilmiştir. Bu kapsamda yapay zekanın eğitimde kullanılmasına ilişkin çalışmalarda aşağıdaki araştırma sorularına cevap aranmıştır;

1. Çalışmalar, belirlenen yapay zeka tekniklerine göre sınıflandırıldığında nasıl dağılım göstermektedir?

2. Çalışmalar yapıldığı yıllara göre nasıl dağılım göstermektedir?

3. Çalışmalarda belirtilen anahtar kelimelere göre dağılımı nasıldır?

4. Çalışmaların araştırma yöntemlerine göre dağılımı nasıldır?

5. Çalışmalarda ele alınan çalışma grubunun dağılımı nasıldır?

6. İncelenen çalışmaların türü (tez, makale) nasıl bir dağılım göstermektedir?

\section{Yöntem}

\section{Araştırma Modeli}


Araştırmada yapay zeka tekniklerinin eğitimde kullanımı ile ilgili çalışmaları incelemek amacıyla betimsel içerik analizi yöntemi kullanılmıştır. İçerik analizi birbiri ile ilgili ve benzer nitelikte olan verileri belirlenen kavramlar ve temalar kapsamında bir araya getirmek ve bunları okuyucunun anlayabileceği bir biçimde düzenleyerek yorumlamaktır (Yıldırım ve Şimşek, 2006). İçerik analizi, belirli kurallar çerçevesinde bir metne ait sözcüklerinin daha küçük içerik kategorileri olarak ifade edilerek özetlendiği sistemli ve tekrarlanabilir bir tekniktir (Büyüköztürk, Çakmak, Akgün, Karadeniz ve Demirel, 2009).

\section{Verilerin Toplanması}

Araştırma kapsamında Ulusal Tez Merkezi'nde yayınlanmış yüksek lisans ve doktora tezleri, Türkiye adresli uluslararası dergilerde yayınlanmış makaleler ve Türkiye'de eğitim alanında yayınlanan hakemli dergiler, eğitim fakültesi dergileri ve konuyla ilgili olarak çevrim içi yayınlanan dergiler incelenmiştir. Tez taramaları, Ulusal Tez Merkezi web sitesinde "gelişmiş tarama" kısmından gerçekleştirilmiştir. Türkiye adresli makalelere ulaşmak için öncelikle Danişman ve diğerleri (2016) ile Seferoğlu (2021) tarafindan yapılan dergi listeleri kullanılmıştır. Daha sonra DergiPark ortamında arama yapılmıştır. Sonrasında Google Scholar'da Türkçe anahtar kelimelerle arama yapılmıştır. Yapılan tarama sonucunda tekrarlı ulaşılan çalışmalar ayıklanmıştır.

Çalışmaların taranmasında "yapay zeka”, "bulanık mantık”, “yapay sinir ağları”, “uzman sistemler”, “zeki etmenler”, “zeki öğretim sistemi” anahtar kelimeleri kullanılmıştır. Tarama, 2019 yılı Mayıs ayında gerçekleştirilmiştir. Araştırma kapsamında tespit edilen çalışmalara ait sayısal veriler Tablo 1'de belirtilmiştir.

Tablo 1. İncelenen makale ve tezlerin türlerine göre dağılımı

\begin{tabular}{lc}
\hline Araştırmada İncelenen Çalışmalar & Adet \\
\hline Ulusal Tez Merkezi & \\
Yüksek Lisans Tezleri & 11 \\
Doktora Tezleri & 7 \\
SSCI İndeksli Eğitim Dergilerinde Yayınlanan Makaleler & 8 \\
Eğitim Alanındaki Diğer Dergilerde Yayınlanan Makaleler & 11 \\
\hline
\end{tabular}

Çalışmada Ulusal Tez Merkezinde yayınlanan yüksek lisans ve doktora tezleri, eğitim fakültesi dergileri, eğitim alanında yayınlanan 4'ü SSCI 'de dizinlenen toplamda 27 dergi taranmıştır. Tarama sonucunda 52 çalışmaya ulaşılmış, çalışma alanı yapay zekanın eğitimde uygulanması ile doğrudan ilişkili olmayan 15 çalışma tarama kapsamından çıkarılmıştır. 
Araştırma kapsamında incelenmek üzere toplamda 37 kaynak belirlenmiş ve bu çalışmalar Tablo 2' de gösterilmiştir.

Tablo 2: Araştırma kapsamında incelenmek üzere tarama sonucunda belirlenen kaynaklar

\begin{tabular}{|c|c|c|c|}
\hline Sira & Kaynak & Yayınlandığı Yer & Tür \\
\hline 1 & Keleş (2007) & Ulusal Tez Merkezi & Doktora Tezi \\
\hline 2 & Özbek (2007) & Ulusal Tez Merkezi & Doktora Tezi \\
\hline 3 & Demir (2008) & Ulusal Tez Merkezi & Doktora Tezi \\
\hline 4 & Özdemir (2009) & Ulusal Tez Merkezi & Doktora Tezi \\
\hline 5 & Kahraman (2009) & Ulusal Tez Merkezi & Doktora Tezi \\
\hline 6 & Erümit (2014) & Ulusal Tez Merkezi & Doktora Tezi \\
\hline 7 & Erdemir (2015) & Ulusal Tez Merkezi & Doktora Tezi \\
\hline 8 & Kaya (2005) & Ulusal Tez Merkezi & Yüksek Lisans Tezi \\
\hline 9 & Dönmez (2006) & Ulusal Tez Merkezi & Yüksek Lisans Tezi \\
\hline 10 & Akgöl (2006) & Ulusal Tez Merkezi & Yüksek Lisans Tezi \\
\hline 11 & Erkoç (2008) & Ulusal Tez Merkezi & Yüksek Lisans Tezi \\
\hline 12 & Körez (2009) & Ulusal Tez Merkezi & Yüksek Lisans Tezi \\
\hline 13 & Aktaş (2010) & Ulusal Tez Merkezi & Yüksek Lisans Tezi \\
\hline 14 & Dikbıyık (2013) & Ulusal Tez Merkezi & Yüksek Lisans Tezi \\
\hline 15 & Ar1 (2013) & Ulusal Tez Merkezi & Yüksek Lisans Tezi \\
\hline 16 & Akdemir (2016) & Ulusal Tez Merkezi & Yüksek Lisans Tezi \\
\hline 17 & Namlı (2016) & Ulusal Tez Merkezi & Yüksek Lisans Tezi \\
\hline 18 & Yağc1 (2018) & Ulusal Tez Merkezi & Yüksek Lisans Tezi \\
\hline 19 & Akpınar (1999) & Eğitim ve Bilim Dergisi & Makale \\
\hline 20 & $\begin{array}{l}\text { Tüfekçi ve Köse } \\
\text { (2013) }\end{array}$ & Hacettepe Üni. Eğitim Fakültesi Dergisi & Makale \\
\hline 21 & $\begin{array}{l}\text { Güler ve } \\
\text { Yücedağ (2017) }\end{array}$ & Hacettepe Üni. Eğitim Fakültesi Dergisi & Makale \\
\hline 22 & Bahadır (2016) & $\begin{array}{l}\text { Kuram ve Uygulamada Eğitim Bilimleri } \\
\text { (SSCI) }\end{array}$ & Makale \\
\hline 23 & Kayri (2015) & $\begin{array}{l}\text { Kuram ve Uygulamada Eğitim Bilimleri } \\
\text { (SSCI) }\end{array}$ & Makale \\
\hline 24 & $\begin{array}{l}\text { İçöz, Şanalan, } \\
\text { Çakar, Özdemir } \\
\text { ve Kaya (2015) }\end{array}$ & $\begin{array}{l}\text { Kuram ve Uygulamada Eğitim Bilimleri } \\
\text { (SSCI) }\end{array}$ & Makale \\
\hline 25 & Demir (2015) & $\begin{array}{l}\text { Kuram ve Uygulamada Eğitim Bilimleri } \\
\text { (SSCI) }\end{array}$ & Makale \\
\hline 26 & Aslan (2014) & $\begin{array}{l}19 \text { Mayıs Üniversitesi Eğitim Fakültesi } \\
\text { Dergisi }\end{array}$ & Makale \\
\hline 27 & $\begin{array}{l}\text { Karacı ve Arıc1 } \\
(2012)\end{array}$ & Politeknik Dergisi & Makale \\
\hline
\end{tabular}


Aktaş ve Doğan

Bilişim Teknolojileri Dergisi

Makale (2011)

29 Doğan ve Kubat (2008)

30 Köse ve Tüfekçi (2015)

31 Kaya ve Korkmaz (2007)

32 Önder (2002)

33 Tezbaşaran, Gelbal (2018)

34 Özek (2015)

35 Doğan ve Ar1 (2015)
Bilișim Teknolojileri Dergisi

Pegem Eğitim ve Öğretim Dergisi

Ahi Evran Üniversitesi Kırşehir Eğitim Makale Fakültesi Dergisi

Sakarya Üni. Eğitim Fakültesi Dergisi Makale

Mersin Üniversitesi Eğitim Fakültesi Makale Dergisi

Eğitim ve Öğretim Araştırmaları Dergisi Makale

Eğitim ve Öğretim Araştırmaları Dergisi Makale

Eğitim ve Öğretim Araştırmaları Dergisi Makale

Zeki Sistemler Teori Ve Uygulamaları Makale Dergisi

\section{Verilerin Analizi}

Çalışmaların incelenmesinden elde edilen veriler Microsoft Excel programına aktarılmış, değerlendirilen veriler grafik, frekans ve yüzde tabloları ile betimsel olarak ifade edilmiştir.

\section{Bulgular}

Çalışmada elde edilen bulgular, araştırma soruları doğrultusunda, kullanılan tekniklerin yıllara göre dağılımı, anahtar kelimeler, araştırma yöntemleri, incelenen çalışma grupları ve yayın türlerine göre incelenmiştir.

\section{Kullanılan Yapay Zeka Teknikleri ve Yıllara Göre Dağılımı}

Araştırma kapsamında incelenen çalışmalara ilişkin yayın sayılarının yıllara göre dağılımı, kullanılan yapay zeka tekniklerinin çalışmalarda kullanım oranı Tablo 3’te sunulmuştur. ZÖS, yapay zeka tekniklerinin en çok ele alındığı, eğitimin yapay zekaya uygulanma alanı olarak karşımıza çıktığı için diğer tekniklerle bir arada alınmıştır. 
$\underline{\text { Tablo 3. İncelenen araştırmalarda kullanılan yapay zeka tekniklerinin yıllara göre dağılımı }}$

\begin{tabular}{|c|c|c|c|c|c|c|c|c|}
\hline Y1l & $\begin{array}{l}\text { Bulanık } \\
\text { Mantık }\end{array}$ & $\begin{array}{l}\text { Yapay } \\
\text { Sinir } \\
\text { Ağları }\end{array}$ & $\begin{array}{c}\text { Zeki } \\
\text { Etmenle } \\
\mathrm{r}\end{array}$ & $\begin{array}{c}\text { Uzman } \\
\text { Sistemle } \\
\mathrm{r}\end{array}$ & $\begin{array}{c}\text { Zeki } \\
\text { Öğretim } \\
\text { Sistemleri }\end{array}$ & $\begin{array}{c}\text { Yapay } \\
\text { Zeka } \\
\text { (Genel } \\
\text { ) }\end{array}$ & $\mathrm{N}$ & Yüzde \\
\hline 1999 & & & & & 1 & & 1 & $\% 2,7$ \\
\hline 2002 & & & & & & 1 & 1 & $\% 2,7$ \\
\hline 2005 & & & & & 1 & & 1 & $\% 2,7$ \\
\hline 2006 & & & 1 & & 1 & & 2 & $\% 5,4$ \\
\hline 2007 & & & 1 & & 2 & & 3 & $\% 8,1$ \\
\hline 2008 & & & 1 & 1 & & & 2 & $\% 5,4$ \\
\hline 2009 & 1 & & & & 2 & & 3 & $\% 8,1$ \\
\hline 2010 & & & & & 1 & & 1 & $\% 2,7$ \\
\hline 2011 & & & & & 2 & & 2 & $\% 5,4$ \\
\hline 2012 & & & & & 1 & & 1 & $\% 2,7$ \\
\hline 2013 & & & & & 2 & 1 & 3 & $\% 8,1$ \\
\hline 2014 & & & & 1 & 1 & 1 & 3 & $\% 8,1$ \\
\hline 2015 & & 2 & & & 3 & 2 & 7 & $\% 18,9$ \\
\hline 2016 & 2 & 1 & & & 1 & & 4 & $\% 10,8$ \\
\hline 2018 & & 2 & & & & 1 & 3 & $\% 8,1$ \\
\hline Toplam & 3 & 5 & 3 & 2 & 18 & 6 & 37 & $\% 100$ \\
\hline Yüzde & $\% 8,1$ & $\% 13,5$ & $\% 8,1$ & $\% 5,4$ & $\% 48,6$ & $\% 16,2$ & $\% 100$ & \\
\hline
\end{tabular}

Tablo 3 incelendiğinde çalışmaların en çok ZÖS’ün ele aldığı $(\% 48,6)$ görülmektedir. Onu, yapay zekanın genel olarak ele alındığı çalışmalar $(\% 16,2)$ ve yapay sinir ağları $(\% 13,5)$ çalışmalarının takip ettiği, uzman sistemler $(\% 5,4)$ ve bulanık mantık $(\% 8,1)$ konulu çalışmaların sınırlı kaldığı görülmektedir. Çalışma sayıları yıllara göre doğrusal olmayan bir değişkenlik göstermektedir. 2006 yılından itibaren çalışmalarda önemli bir artış görülürken, en fazla sayıda çalışma 2015 ve 2016 yıllarında gerçekleştirilmiştir.

\section{Anahtar Kelimelere Göre Dağılımı}

Eğitimde yapay zeka kullanımına ilişkin çalışmaların içerdikleri anahtar kelimeler belirlenmiş ve Şekil 1'de grafiksel olarak gösterilmiştir. 

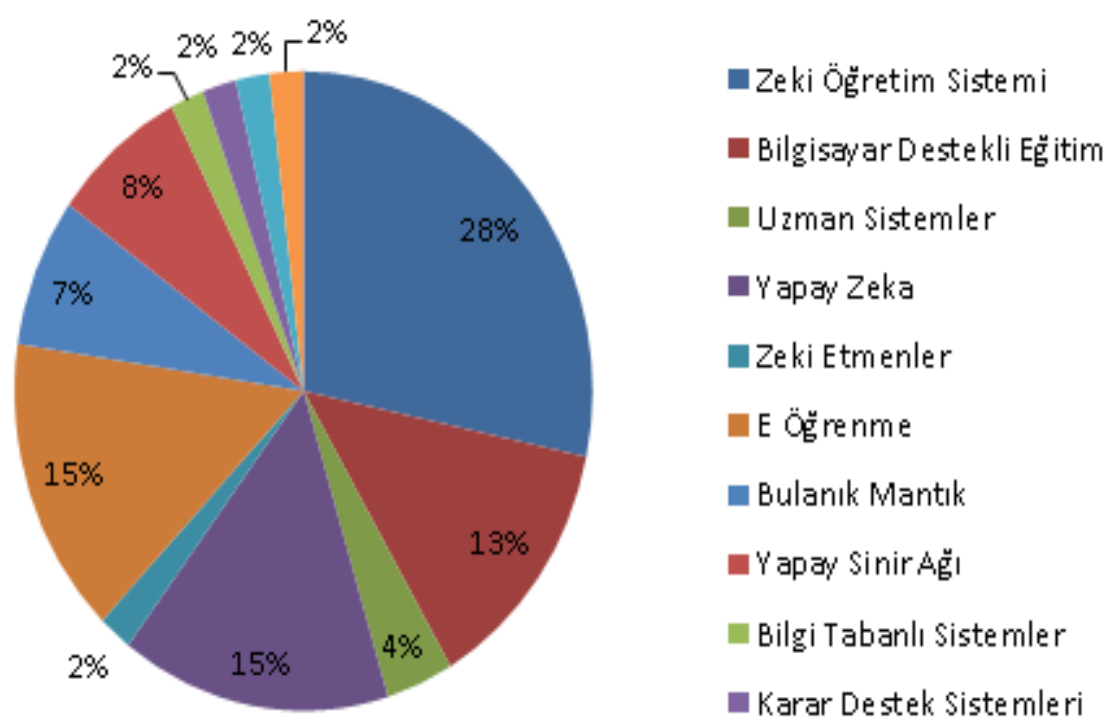

Şekil 1. Çalışmalarda belirlenen anahtar kelimelerin yüzdelik dağılım grafiği

Şekil 1 incelendiğinde çalışmaların önemli bir kısmını zeki öğretim sistemini ele alan çalışmaların (\%28) oluşturduğu görülmektedir. Onu yapay sinir ağı (\%13) çalışmalarının takip ettiği görülmektedir. Yapay zekanın eğitim alanında yapılan çalışmalarda e-öğrenmenin (\%15) diğerlerine göre geniş alan kapladığı görülmektedir.

“Zeki öğretim sistemi” ve “yapay zeka” anahtar kelimeleri ile yapılan araştırmalar, en fazla sayıda çalışmaya ulaşılmasını sağlamaktadır.

\section{Araştırma Yöntemlerine Göre Dağılımı}

Araştırma konularının araştırma yöntemlerine göre dağılımı Tablo 4‘de gösterilmektedir.

Tablo 4. Araştırma konularının, araştırma yöntemlerine göre dağılımı

\begin{tabular}{lcc}
\hline Araştırma Yöntemi & Toplam & Yüzde \\
\hline Nitel & 5 & $\% 13,5$ \\
Nicel & 7 & $\% 19,9$ \\
Karma & 8 & $\% 21,6$ \\
Tasarım ve geliştirme & 17 & $\% 45,9$ \\
\hline
\end{tabular}

Tablo 4 incelendiğinde çalışmaların genellikle tasarım ve geliştirmeye yönelik çalışmalar $(\% 45,9)$ olduğu, bunu karma $(\% 21,6)$ ve nicel $(\% 19,9)$ yöntemlerin takip ettiği görülmektedir. Eğitimde yapay zeka alanında nitel yöntemlerle desenlenmiş çalışma sayısının $(\% 13,5)$ diğerlerine göre daha az olduğu görülmektedir. 


\section{Ele Alınan Çalışma Grubuna Göre Dağılımı}

İncelenen çalışmalarda tespit edilen çalışma grubu dağılımı Şekil 2'de grafiksel olarak gösterilmiştir.

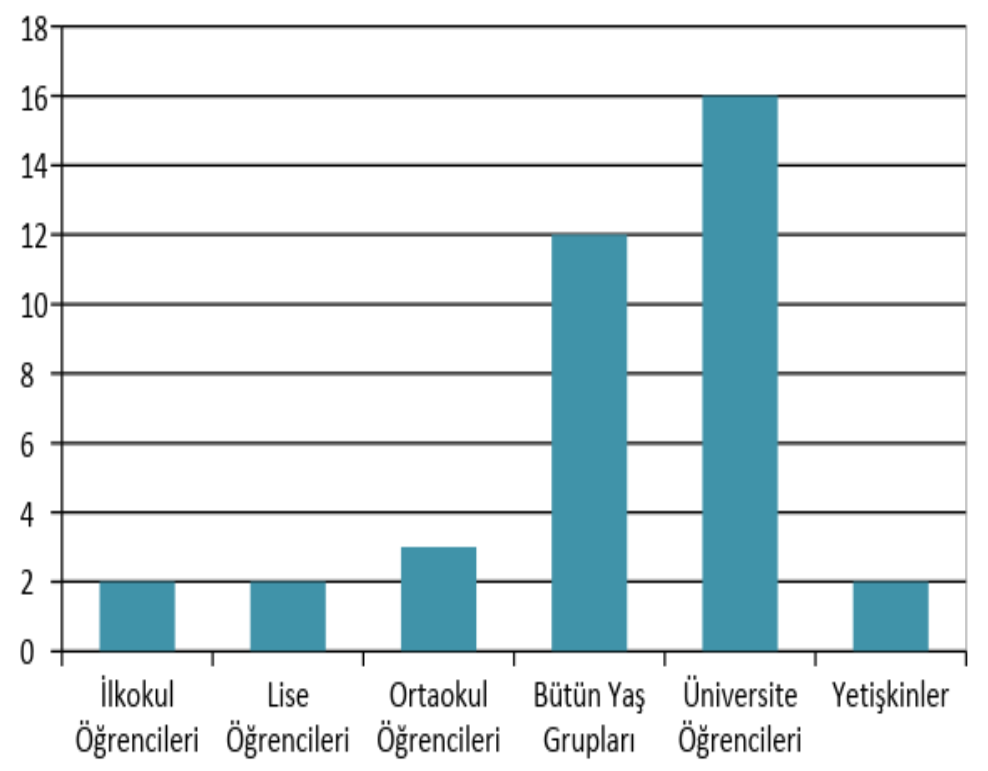

Şekil 2. İncelenen çalışmalarda tespit edilen çalışma grubu düzeylerinin dağılımı

Şekil 2'de görüldüğü gibi yapılan çalışmaların \%43' ünün üniversite öğrencilerini, \%32,4' ünün ise eğitim durumu gözetmeksizin tüm yaş grupları üzerine gerçekleştirildiği görülmektedir. İlköğretim ve lise öğrencileri düzeyindeki çalışma gruplarında, eğitimde yapay zeka çalışması diğer çalışma gruplarına göre daha az sayıdadır.

\section{Yayınlara Göre Dağılımı}

Araştırmada incelenen çalışmaların yayınlandığı dergilere göre grafiksel dağılımı Şekil 3’te gösterilmektedir. 


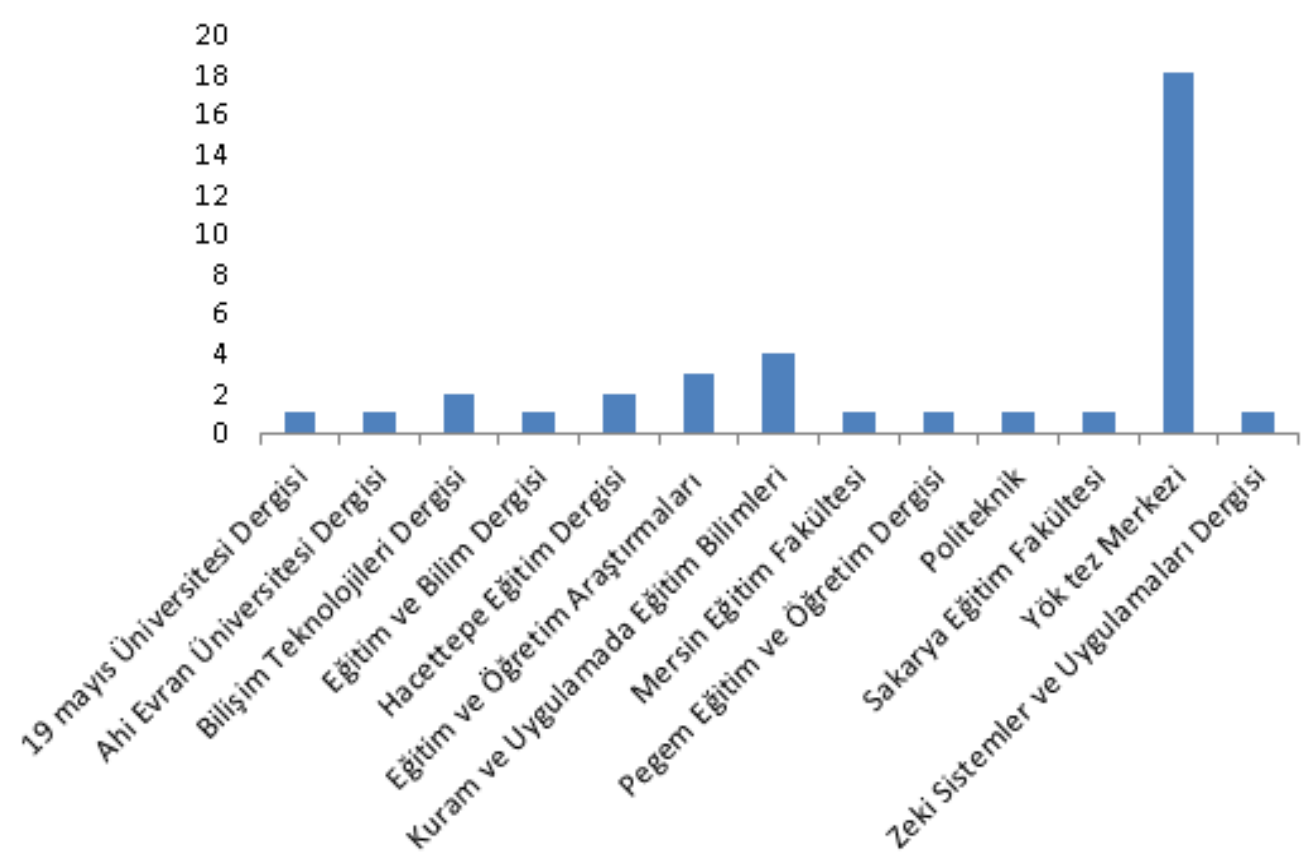

Şekil 3. İncelenen çalışmaların yayınlandığı dergilere göre dağılımı

Eğitimde yapay zeka kullanımı konusunda yapılan çalışmaların çok önemli bir kısmı yüksek lisans ve doktora tezi olarak yayınlandığı Şekil 3’te görülmektedir. Eğitimle ilgili Türkiye adresli dergilerde konu ile ilgili az sayıda makaleye ulaşılabilmektedir.

\section{Tartışma, Sonuç ve Öneriler}

$\mathrm{Bu}$ araştırmada, yapay zeka konularının eğitimde kullanım alanları ile ilgili sistematik literatür çalışması ortaya konulmuştur. Elde edilen bulgular ışığında aşağıdaki sonuçlara ulaşı1lmıştır.

Çalışmada 1999-2018 yılları arasında en çok çalışmanın yüksek lisans ve doktora tezi olarak yayınlandığı, bunu eğitim dergileri ve eğitim fakülteleri dergilerinin takip ettiği belirlenmiştir. Yapay zeka konusunda YÖK tez merkezinde ve eğitim dergilerinde çok sayıda yayın bulunmasına karşın eğitim konulu yapay zeka yayınlarının sayısının her geçen yıl arttığı görülmektedir.

Yapay zeka tekniklerinin eğitimde kullanılmasına ilişkin çalışmalar çoğunlukla tasarım ve geliştirme yöntemi ile gerçekleştirilmiştir. Bu durum yapay zeka konusunda yeni teknolojilerin geliştirildiğini göstermektedir. Yeni geliştirilen bu teknolojilerin farklı araştırma desenleri ile kullanılarak etkilerinin belirlenmesi çalışma alanının zenginleşmesi açısından önemli olacaktır. Nitel çalışmaların sayıca az olduğu görülmektedir. Benzer durum yurtdışındaki yayınlarda da geçerlidir (Tahiru, 2021). 
Ülkemizdeki çalışmalarda çalışmaların sayısının 2010’dan itibaren yükselme eğilimine girdiği ve 2015 yılında önemli ölçüde arttığı belirlenmiştir. Araştırmalar, 2010'dan önce yapay zeka hakkında daha az çalışma olduğunu ve daha sonra yeni teknolojilerin, endüstri 4.0 ile teknolojiyi etkinleştiren birincil anahtar olarak yapay zekayı daha sık benimsemeye başlamasıyla birlikte araştırmaların arttığını ortaya koymuştur (Duan, Edwards, \& Dwivedi, 2019).

Bulgularda zeki öğretim sistemlerinin en çok tercih edilen yapay zeka uygulaması olduğu belirlenmiştir. Zeki öğretim sistemleri farklı yapay zeka tekniklerinin eğitim öğretim amacıyla düzenlenmiş ve bir araya getirilmiş halidir. Arık ve Seferoğlu (2020) da çalışmalarında, yurt dışında ve ülkemizde eğitimde yapay zeka kullanımını konu alan çalışmalarda zeki öğretim sistemi hakkında yapılan çalışmaların çoğunlukta olduğunu belirtmektedir. Yapay zekanın eğitimde kullanılması ile ilgili çalışmalara genel olarak bakıldığında çoğu araştırma ZÖS'ün kullanımı ve işlevi üzerine yoğunlaşmıştır (Tahiru, 2021). Bu çalışmada, arama kriterlerinin eğitim öğretim ile ilgili olduğu için ZÖS ile ilgili çalışmalara ulaşılması beklenen bir durumdur. Bu tekniğin esas amacının eğitim öğretim olması, çalışmalarda fazla tercih edilmesinin nedeni olarak gösterilebilir. Bunun dişında uzman sistemler, yapay sinir ağları, zeki etmenler, bulanık mantık ve bunların bütüncül olarak düşünüldüğü yapay zeka teknikleri de eğitim öğretim çalışmalarına konu olmaktadır.

İncelenen çalışmalar çalışma gruplarına göre sınıflandırıldığında, çalışmaların \%43,2'sini üniversite öğrencilerinin oluşturduğu belirlenmiştir. Ülkemiz dışında yapılan çalışmalarda da benzer bir eğilim söz konusudur (Arık ve Seferoğlu, 2020). Bunu bütün yaş gruplarını konu alan çalışmalar takip etmektedir. İlkokul ve ortaokul öğrencilerini çalışma grubu olarak alan daha az sayıda çalışma bulunmakla birlikte, okul öncesi dönemdeki çocuklar için gerçekleştirilmiş bir çalışmaya, bu çalışmada incelenen kapsamda rastlanmamıştır. Konu ile ilgili yapılacak çalışmalarda bu durumun göz önünde bulundurulması, okul öncesi dönem çocukları için de yapay zeka kullanılan eğitim ortamları düzenlenmesinin faydalı olacağı düşünülmektedir (Akdeniz, 2019).

Çalışmalar yayın türlerine göre incelendiğinde tez çalışmalarının çoğunlukta olduğu görülmektedir. Bu tez çalışmalarının makale olarak yayınlanması ile birlikte Türkiye adresli dergilerde eğitimde yapay zeka konulu makalelerin sayısının artması beklenmektedir. Richter, Marin, Bond ve Gouverneur (2019), yüksek öğretimde yapay zekayı inceledikleri sistematik literatür taraması çalışmalarında, çalışmaların yarısının ABD, Çin, Tayvan ve Türkiye'den 
olduğunu ve Türkiye'nin dördüncü sırada olduğunu belirtmektedir. Ülkemizdeki araştırmacılar bu konuda yaptıkları çalışmaları uluslararası dergilerde yayınlamayı tercih etmektedir. Türkiye'de, eğitimde yapay zeka alanında yapılan çalışmaların resminin daha açık görülmesi için uluslararası yayınları ele alan sistematik literatür tarama çalışmalarının yapılması yararı olacaktır.

$\mathrm{Bu}$ çalışma kapsamında yapay zeka ile doğrudan bağlantılı tara kelimeleri seçilmiştir. Öğrenme analitikleri ve eğitsel veri madenciliği gibi konular, yapay zeka tekniklerini kullanmakla beraber, bu konuları işleyen çalışmaların özet ya da anahtar kelimelerinde bu araştırma bağlamında ele alınan anahtar kelimelerin yer almadığı görülmüştür (Bilen, Hotaman, Aşkın ve Büyüklü, 2014). Ayrıca doğal dil işleme, görüntü işleme gibi konuların kapsama alındığı çalışmaların yapılması önerilir.

Çalışmanın sonuçları yapay zekanın eğitimde kullanılmasının, ülkemizde son yıllarda gelişen bir araştırma alanı olduğunu göstermektedir. Bu araştırma kapsamında Türkiye adresli ve Türkçe alanyazın ele alınmıştır. Web of Science ya da ERIC veritabanları bağlamında da benzer çalışmaların yapılması yararlı olacaktır.

Çalışma gruplarının genellikle yükseköğretim gruplarından oluştuğu görülmektedir. Okul öncesi dönem ve yaşam boyu öğrenme konusunda çalışmaların yapılması alanyazına katkı sağlayacaktır.

Tasarım ve geliştirme çalışmalarının yoğunlukta olması ülkemizde yapay zeka konusunda bir üretim olduğunun göstergesidir. $\mathrm{Bu}$ çalışmaların artması ve geliştirilen ortamların etkilerinin incelendiği çalışmaların yapılması yararlı olacaktır. Diğer yandan çalışma durumlarının kapsamlı olarak ele alındığı nitel araştırmaların artması, yapay zekanın eğitimde kullanılmasına ilişkin daha derinlemesine bilgiler sunacaktır.

\section{Makalenin Bilimdeki Konumu}

Bilgisayar ve Öğretim Teknolojileri Eğitimi/Eğitimde Teknoloji Kullanımı

\section{Makalenin Bilimdeki Özgünlüğü}

Literatürde, eğitimde yapay zeka kullanımına ilişkin farklı çalışmalar yer almaktadır. Yapılan çalışmaları; yöntemi, çalışma grubu ve sonuçları açısından inceleyerek alanyazında eksikliği bulunan konuları belirleme amacına sahip olan bir çalışmaya rastlanmamaktadır. $\mathrm{Bu}$ nedenle eğitimde yapay zeka kullanımına ilişkin çalışmalar ve sonuçları incelenmiş, genel eğilimleri ve eksiklikleri ortaya konulmuştur. Araştırmadan elde edilen bulguların eğitimde yapay zeka kullanımı hakkında yapılacak çalışmalara rehberlik etmesi amaçlanmaktadır. 


\section{Kaynaklar}

Akdeniz, M. (2019). Okul öncesi çocuklarına yönelik yapay zeka tabanlı akıllı oyuncaklar: tasarım tabanlı bir çalışma. Yüksek Lisans tezi, Fen Bilimleri Enstitüsü, Afyon Kocatepe Üniversitesi, Afyonkarahisar.

Arık, G., \& Seferoğlu, S.S. (2020). Eğitimde Yapay Zekâ Çalışmaları: Araştırma Eğilimleri, Karşılaşılan Zorluklar ve Çözüm Önerileri. Nabiyev, V. \& Erümit, A.K. (Ed.). Eğitimde Yapay Zeka Kuramdan Uygulamaya içinde. Ankara: Pegem Yayıncılık

Aydede, M. N. (2009). Aktif öğrenme uygulamalarının öğrencilerin kendi kendine öğrenme ve eleştirel düşünme becerileri ile öz yeterlilik inançlarına ve erişilerine etkisi. Doktora tezi, Eğitim Bilimleri Enstitüsü, Dokuz Eylül Üniversitesi, İzmir.

Baker, T., \& Smith, L. (2019). Educ-AI-tion rebooted? Exploring the future of artificial intelligence in schools and colleges. Erişim adresi: https://media.nesta.org.uk/documents/Future_of_AI_and_education_v5_WEB.pdf

Bekleriç, G. (2003). Yapay zekada zeki etmenler ve uygulamaları. Doktora tezi, Fen Bilimleri Enstitüsü, İstanbul Teknik Üniversitesi, İstanbul.

Bilen, Ö., Hotaman, D., Askin, Ö. E., \& Büyüklü, A. H. (2014). Analyzing the School Performances in terms of LYS Successes through using Educational Data Mining Techniques: Istanbul Sample, 2011. Egitim ve Bilim, 39(172).

Bolat, B., Erol, K. O., \& İmrak, C. E. (2004). Genetic algorithms in engineering applications and the Function of operators. Sigma, 4, 264-271.

Büyüköztürk, Ş., Kılıç Çakmak, E., Akgün, Ö. E., Karadeniz, Ş. ve Demirel, F. (2009). Bilimsel araştırma yöntemleri. Ankara: Pegem Akademi Yayınları.

Danişman, Ş., Yalçın, M., Çiftçi, Ş. K., Tosuntaş, Ş. B., Sölpük, N., Ay, Y., Karadă̆, E. ve Yücel, E. (2016a). Türkiye'de eğitim bilimleri alanında yayımlanan dergilerin bilimsel yayın haritası: Dergi etki faktörleri üzerine bir inceleme. Kuram ve Uygulamada Eğitim Yönetimi, 22(4), 483-506. Doğan, N. ve Aktaş, B. (2011). Promath: Web tabanlı zeki öğretim sistemleri için düzenleyici modül uygulaması. Bilişim Teknolojileri Dergisi, 4 (2), 25-33.

Danişman, Ş., Yalçın, M., Çiftçi, Ş. K., Tosuntaş, Ş. B., Sölpük, N., Ay, Y., ... \& Yücel, C. (2016b). Türkiye'de eğitim bilimleri alanında yayımlanan dergilerin bilimsel yayın haritas1: Dergi etki faktörleri üzerine bir inceleme. Kuram ve Uygulamada Ĕ̈itim Yönetimi, 22(4), 483-506. 
Dogan, N., \& Aktaş, B. (2011) Promath: web tabanlı zeki öğretim sistemleri için düzenleyici modül uygulamas1. Bilişim Teknolojileri Dergisi, 4(2).

Duan, Y., Edwards, J. S., \& Dwivedi, Y. (2019). Artificial intelligence for decision making in the era of Big Data - evolution, challenges and research agenda. International Journal of Information Management, 48, 63-71. doi:10.1016/j.ijinfomgt.2019.01.021

Erçetin, Ö. Z. ve Baykoç, Ö. F. (2004). Tedarikçi seçimi problemine karar teorisi destekli uzman sistem yaklaşımı. Gazi Üniversitesi Mühendislik-Mimarlık Fakültesi Dergisi, 19(3), 276-286.

Hamzaçebi, C. ve Kutay, F. (2004). Yapay sinir ağları ile Türkiye elektrik enerjisi tüketiminin 2010 yılına kadar tahmini. Gazi Üniversitesi Mühendislik-Mimarlık Fakültesi Dergisi, 19(3), 227-233.

Hasanov, A., Laine, T. H., \& Chung, T. S. (2019). A survey of adaptive context-aware learning environments. Journal of Ambient Intelligence and Smart Environments, 11(5), 403-428.

How, M. L. ve Hung, W. L. D. (2019). Educing AI-Thinking in Science, Technology, Engineering, Arts, and Mathematics (STEAM) Education. Education Sciences, 9(3), 18

Kalem, S. ve Fer, S. (2003). Aktif öğrenme modeliyle oluşturulan öğrenme ortamının öğrenme, öğretme ve iletişm sürecine etkisi. Educational Sciences: Theory \& Practice, 3(2), 433461.

Nist. L. S. \& Holschuh. P. J. (2000). Active learning strategies for college success. London: Ally and Bacon.

Öngöz, S. (2020). Yapay zeka teknolojinin kullanıldığ1 yeni nesil öğretim materyalleri. Nabiyev, V. \& Erümit, A.K. (Ed.). Eğitimde Yapay Zeka Kuramdan Uygulamaya içinde. Ankara: Pegem Yayıncılık

Öztemel, E. (2003). Yapay sinir ağları. İstanbul: PapatyaYayıncılık.

Pala, F.K. (2020). Makine öğrenmesi ve eğitim sistemine getirdikleri. Nabiyev, V. \& Erümit, A.K. (Ed.). Eğitimde Yapay Zeka Kuramdan Uygulamaya içinde. Ankara: Pegem Yayıncılık

Piramuthu, S. (2005). Knowledge-based web-enabled agents and intelligent tutoring systems. IEEE Transactions on Education, 48(4), 750-756.

Retto, J. (2017). Sophia, first citizen robot of the world, ResearchGate https://www. researchgate. net, pp. 2-9. 
Richter, Z., Marín, O., Bond, V.I., \& Gouverneur, F. (2019). Systematic review of research on artificial intelligence applications in higher education-where are the educators?. International Journal of Educational Technology in Higher Education, 16(1), 1-27.

Seferoğlu, S.S. (2021). Süreli $\quad$ Yayınlar. Erişim adresi http://yunus.hacettepe.edu.tr/ sadi/egitim/dergi.html

Somyürek, S. (2009). Uyarlanabilir öğrenme ortamları: Eğitsel hiper ortam tasarımında yeni bir paradigma. Bilişim Teknolojileri Dergisi, 2(1).

Syed, A.B. \& Zoga, A.C. (2018). Artificial intelligence in radiology: current technology and future directions Semin. Musculoskelet. Radiol., 22, pp. 540-545

Şahin, İ. (2008). Uzman sistem kullanarak 2B'lu izdüşümlerden katı model oluşturma, Doktora Tezi, Fen Bilimleri Enstitüsü, Gazi Üniversitesi, Ankara.

Tahiru, F. (2021). AI in Education: A Systematic Literature Review. Journal of Cases on Information Technology (JCIT), 23(1), 1-20.

Uğur, A. ve Kınacı, A. C. (Aralık, 2006). Yapay zeka teknikleri ve yapay sinir ağları kullanılarak web sayfalarının sınıflandirılması. XI. Türkiye'de Internet Konferansı, TOBB Ekonomi ve Teknoloji Üniversitesi, 21-23 Aralık, Ankara,

Ünal, O. ve Uygunoğlu, T. (2005). Seyitömer uçucu külünün betonun basınç dayanımına etkisi üzerine bulanık mantık yaklaşımı. Yapı Teknolojileri Elektronik Dergisi, 1(1), 13-20.

Yıldırım, A. ve Şimşek, H. (2006). Sosyal bilimlerde nitel araştırma yöntemleri (5. baskı). Ankara: Seçkin Yayıncılık.

\section{Summary}

\section{Statement of Problem}

Today, with the adoption of new teaching understandings, topics such as how to achieve more effective learning, what characteristics should educational materials that will be designed for effective learning carry are being explored. One of the methods developed for permanent learning is active learning. Active learning is a learning situation in which students are active, using their mental abilities, and the teacher is in the position of the person who transmits information, guides, and facilitates learning (Kalem and Fer, 2003). The most important point in the active learning approach is that the student is responsible for the self-learning process (Aydede, 2009). In the process of self-learning, teachers should determine when and how 
children will use mental strategies, encourage them to learn, and ensure that students are engaged in complex thinking structures (Nist, 2000). The materials suitable for learning are needed in the student's self-learning process. Educational materials and software are equipped with artificial intelligence technology and have the ability to think, abstract, learn, adapt to new situations, and interact as intelligent creatures (Uğur and Kınacı, 2014). With these features, artificial intelligence technology is used in conjunction with other learning methods, especially active learning, and the number of researches on this subject is increasing day by day. In the literature, it is seen that there is a limited number of systematic literature studies on the use of artificial intelligence in education.

This study aims to examine the work conducted in Turkey on the use of artificial intelligence techniques in education y comprehensively and holistically and to reveal the methodical dimensions and general trends of the studies. For this purpose, graduate theses published between 1999-2018 on the use of artificial intelligence techniques in education, articles published in educational journals and international journals related to Turkey were scanned and descriptive content analysis was carried out. In this context, answers to the following research questions were sought in the studies on the use of artificial intelligence in education:

1. How are the studies distributed when classified according to the artificial intelligence techniques used?

2. How are the studies distributed according to the years they were conducted?

3. What is the distribution according to the keywords specified in the studies?

4. How is the distribution of studies according to research designs?

5. What is the distribution of the working group dealt with in the studies?

6. How is the distribution of the types of studies (thesis, article) examined?

\section{Methods}

This study is designed as a descriptive content analysis in which studies on the use of artificial intelligence techniques in education are examined and evaluated from an educational perspective. For this purpose, artificial intelligence techniques were primarily examined. The teaching materials developed with these techniques and the use of these materials are expressed based on the literature. The prominent features of the studies were examined and answers were sought for the research questions. 
As part of the research, master's and doctoral theses were published in the National dissertation center, articles published in international journals with Turkish addresses and peerreviewed journals published in the field of education in Turkey, journals of educational faculties, and online journals on the subject were studied.

Keywords "artificial intelligence", "fuzzy logic", "artificial neural networks", “expert systems", "Intelligent agents", "intelligent tutoring system" were used in the search of the studies. Master's and doctoral theses published in the National Dissertation Center, Journals of the Faculty of Education belonging to 26 universities, 27 journals published in the field of education, 4 of which are SSCI-like, were scanned for the study. As a result of the scan, 52 resources were found, and 15 studies whose field of study was not directly related to the application of artificial intelligence in education were removed from the scan list.

The data obtained from the examination of the studies were transferred to the Microsoft Excel program and the evaluated data were expressed descriptively with graphics, frequency, and percentage tables.

\section{Findings and Discussions}

When the distribution of the publications on the use of artificial intelligence techniques in education was examined, it was determined that the studies focused on the most intelligent teaching systems, followed by the studies of artificial intelligence and artificial neural networks. It is seen that studies on expert systems and fuzzy logic are limited. The number of studies shows a nonlinear variation by years. While there has been a significant increase in studies since 2006, the highest number of studies were carried out in 2015 and 2016.

Researchers conducted with the keywords of "intelligent tutoring system, artificial intelligence and computer-aided education” ensure the highest number of studies. When analyzed according to the methods of the determined studies, it was observed that the studies were generally aimed at design and development. It is seen that these studies are followed by quantitative and mixed methods.

When the studies are analyzed according to their samples, it is seen that $43 \%$ of the studies were carried out on university students and 32.4\% on all age groups regardless of their educational status. The artificial intelligence studies in education are limited in the sample of primary and high school students. 
A very important part of the studies on the use of artificial intelligence in education has been published as masters and doctoral dissertations. A limited number of resources related to the subject can be accessed in journals with Turkish addresses related to education.

\section{Conclusions and Recommendations}

Although there are many publications in the Higher Education Institution Thesis Center and educational journals on artificial intelligence, the limited number of artificial intelligence publications on education shows that research on the subject is insufficient in Turkey.

Studies on the use of artificial intelligence techniques in education have mostly been carried out by design and development methods. Few studies have been conducted with other research methods. Considering this situation in future studies may be important in terms of enriching the work to be conducted in the field. It has been determined that the number of studies in the literature has increased significantly in 2015. It can be said that this result is due to the process of integrating technology into education and the intensification of studies in this field.

In the findings, it was determined that intelligent teaching systems were the most preferred method. Intelligent teaching systems are the arrangement and combination of different artificial intelligence methods for educational purposes. The fact that the main purpose of this method is education can be shown as the reason why this method is highly preferred in education and training studies. Apart from this, expert systems, artificial neural networks, intelligent factors, fuzzy logic and artificial intelligence technique, where these are considered holistic, are also subject to educational studies.

When the studies examined were classified according to their samples, it was determined that $43.2 \%$ of the sample was made up of university students. This is followed by studies on all age groups. Although there are a limited number of studies for Primary School students, there are no studies conducted for preschool children. It is believed that it will be useful to consider this situation in studies on this issue, as well as to organize educational environments using artificial intelligence technology for children. When the studies conducted are examined, it is seen that education software and distance education systems are generally emphasized. It has been determined that the studies on 3D educational materials developed with artificial intelligence techniques are insufficient. It will be beneficial for children to develop 3D materials with artificial intelligence technology that they can interact with and touch. 
YYÜ Eğitim Fakültesi Dergisi (YYU Journal of Education Faculty), 2021; 18(1)912-932,http://efdergi.yyu.edu.tr,

It is believed that the results of this research may be the source of future research on the use of artificial intelligence in education. More extensive research needs to be done on the study of the use of artificial intelligence techniques in education in Turkey. It is believed that the use of artificial intelligence in instructional material and software development will contribute to student-centered education. 